\title{
Differences in the Characteristics of Dialysis Patients in Japan Compared with Those in Other Countries
}

\author{
Naoki Kimata Ken Tsuchiya Takashi Akiba Kosaku Nitta \\ Department of Blood Purification, Kidney Center, Tokyo Women's Medical University, Tokyo, Japan
}

\section{Key Words}

Hemodialysis · Patient characteristics · Japan · United

States · Europe

\begin{abstract}
Background: Japanese patients undergoing dialysis have an extremely low mortality rate compared with those in the United States and Europe. As shown in the Dialysis Outcomes \& Practice Patterns Study (DOPPS), certain features of dialysis treatment, such as single treatment time and amount of blood flow, are unique to Japan, but factors contributing to the low mortality risk are unclear. Although DOPPS is a multi-country prospective cohort study, the study results may not entirely reflect the real trend in Japan because the number of Japanese institutions participating in the study is small. Summary: In this article, we review the data reported for Japan and other countries and reveal country-specific differences, particularly in patient age distribution and duration of dialysis. Key Messages: The mean age of prevalent dialysis patients is rising every year in Japan, and the proportion of patients undergoing dialysis for long periods of time is also increasing. In addition, the proportion of dialysis patients with diabetes, one of the primary diseases, has increased to a level similar to that observed in Western countries. However, no significant decline in the crude death rate
\end{abstract}

among prevalent dialysis patients has been observed in Japan, presumably because of technological advances in dialysis treatment, but further studies are needed to elucidate the contributing factors.

(c) 2015 S. Karger AG, Basel

\section{Background}

To date, only the Dialysis Outcomes \& Practice Patterns Study (DOPPS) has compared dialysis treatment and outcome between Japan and Western countries. DOPPS has shown that when the relative risk (RR) in Japan was defined as 1.0 , RR was 2.8 in the United States and 3.8 in Europe, indicating an extremely high risk of death in Western countries [1]. DOPPS also reported that compared with Western countries, Japan had a short dialysis treatment time and a low blood flow and filtration volume (single-pool Kt/V), signifying some unique features of dialysis treatment in Japan. However, the factors contributing to the low mortality rate among Japanese prevalent dialysis patients have not been fully elucidated.

Although DOPPS is a multi-country prospective cohort study, which started in 1996 and is continuing to this day, the study results may not entirely reflect the differ-

\section{KARGER 125}

(c) 2015 S. Karger AG, Basel

0253-5068/15/0404-0275\$39.50/0

E-Mail karger@karger.com

www.karger.com/bpu
Naoki Kimata

Department of Blood Purification, Kidney Center

Tokyo Women's Medical University, 8-1 Kawada-cho

Shinjuku, Tokyo 162-8666 (Japan)

E-Mail kimata@kc.twmu.ac.jp 
Table 1. Characteristics of incident and prevalent dialysis patients in Japan, the United States, and Europe

a Incident patients

\begin{tabular}{llll}
\hline & Japan $^{1}$ & United States & \\
\hline No. patients & 38,165 & 114,813 & Europe $^{3}$ \\
Renal replacement therapy, \% & & & 41,643 \\
$\quad$ Hemodialysis* & 97.0 & 89.1 & 77.5 \\
$\quad$ Peritoneal dialysis & 3.0 & 8.2 & 16.0 \\
Mean age, years & 68.5 & 62.5 & 64.5 \\
Men, \% & 67.5 & 57.4 & 63.1 \\
Patients aged $\geq 65$ years, \% & 65.5 & 48.3 & 56.1 \\
\hline
\end{tabular}

b Prevalent patients

\begin{tabular}{llll}
\hline & Japan $^{1}$ & United States & \\
\hline No. of patients & 309,946 & 636,905 & Europe $^{3}$ \\
Blood purification therapy, \% & & & 28,473 \\
$\quad$ Hemodialysis* & 96.9 & 91.0 & 89.7 \\
$\quad 3.1$ & 9.0 & 10.3 \\
Peritoneal dialysis & 66.9 & 62.1 & 60.6 \\
Mean age, years & 63.1 & 57.0 & 61.1 \\
Patients aged $\geq 65$ years, \% & 59.8 & 38.4 & 42.0 \\
\hline
\end{tabular}

Data from the ${ }^{1}$ Japanese Society for Dialysis Therapy, ${ }^{2}$ United States Renal Data System, and ${ }^{3}$ European Dialysis and Transplant Association. ${ }^{*}$ Hemodialysis includes hemodiafiltration and hemofiltration.

ences between Japan and Western countries because only about 60 Japanese institutions are participating in the study involving 9,000 patients.

\section{Comparisons between Incident Dialysis Patients}

The incidence of patients undergoing renal replacement therapy (RRT) at the end of 2012 was 38,165 in Japan (97.0\% undergoing hemodialysis [HD] and 3.0\% undergoing peritoneal dialysis [PD]), compared with 114,813 in the United States $(89.1 \%$ and $8.2 \%$, respectively), and 37,826 in Europe (77.5\% and 16.0\%, respectively) (table 1a). In addition, the number of dialysis patients was 285 per million population in Japan, 359 per million population in the United States, and 150 per million population in Europe [1-3].

In Japan and the United States, the mean age of incident dialysis patients has been increasing since 1982, and there has been a notable increase in the incidence among patients aged $\geq 45$ years, especially among those $\geq 65$ years. However, while the proportion of incident patients aged $\geq 65$ at the end of 2012 was $48.3 \%$ and $56.1 \%$ in the United States and Europe, respectively, the proportion was $65.5 \%$ in Japan, clearly showing aging among Japanese patients undergoing dialysis (table 1a) [1-3].

At the end of 2012, the mean age of incident dialysis patients in Japan was 67.6 years in men and 70.1 years in women. The age pyramid of Japanese dialysis patients divided into 5-year age groups showed the highest incidence in the 75-80 age group in both sexes. In particular, $\geq 1$ in 4 female patients $(27.5 \%)$ were $\geq 80$ years old, revealing a large difference in the age distributions between Japan and other countries.

The number of incident patients with end-stage renal disease (ESRD) due to the primary cause of diabetes or hypertension has been increasing rapidly every year since 1980 in the United States, where the proportion of incident dialysis patients who had diabetes stood at $53.3 \%$ at the end of 2012. Similarly, the annual incidence is increasing for diabetes and for hypertension in Japan. Because of the difference in clinical criteria used to diagnose primary diseases, glomerulonephritis was the most prevalent cause prior to 1997, but since 1998, diabetes has been the 
Fig. 1. Changes in the number of prevalent dialysis patients aged $\geq 65$ years in Japan, the United States, and Europe between 1980 and 2015. JSDT = Japanese Society for Dialysis Therapy; USRDS = United States Renal Data System; EDTA = European Dialysis and Transplant Association.

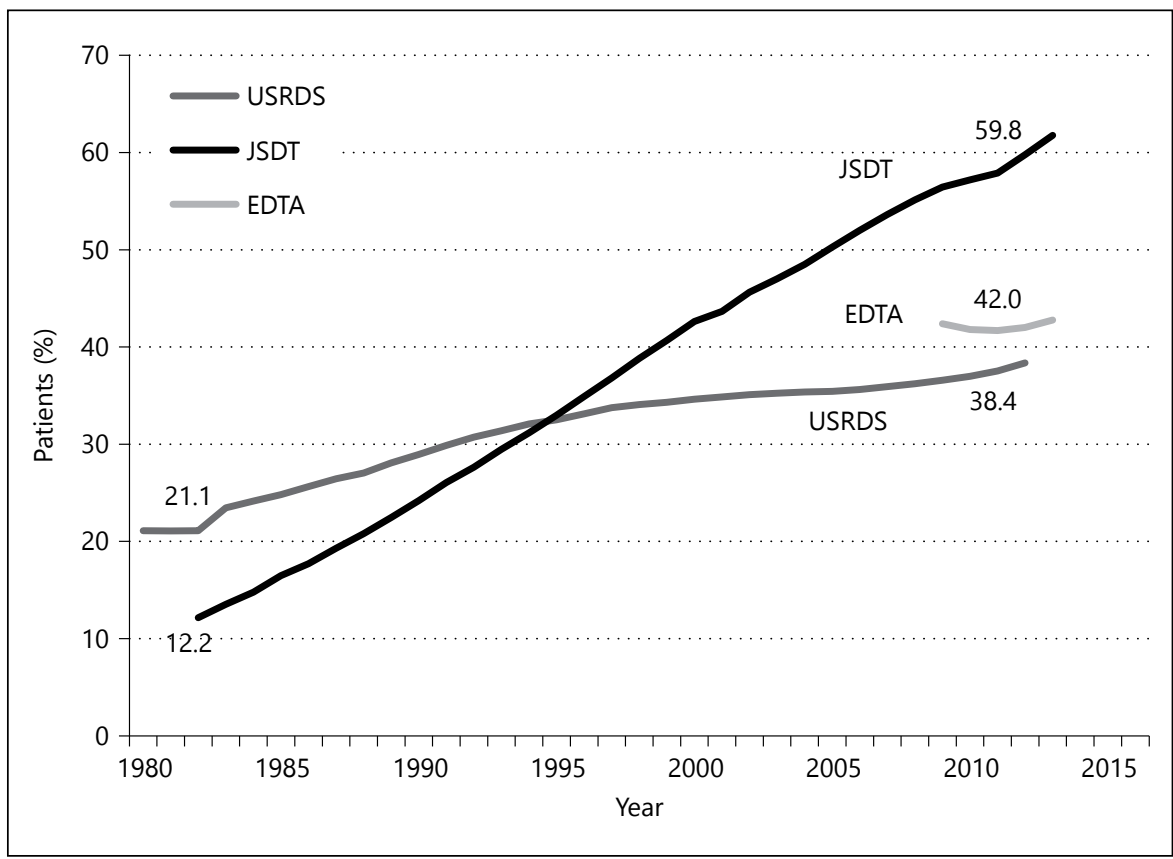

leading primary disease among incident dialysis patients in Japan. Accordingly, the proportion of incident dialysis patients with diabetes increased linearly from $15.6 \%$ in 1983 to $44.2 \%$ in 2012 and is therefore gradually approaching the proportion observed in Western countries.

\section{Comparisons between Prevalent Dialysis Patients}

As of December 2012 the number of prevalent ESRD patients was 309,946 in Japan, 636,905 in the United States, and 284,739 in Europe, with the number increasing each year in all regions (table $1 \mathrm{~b}$ ). The number of patients per million population was $2,365,1,975$, and 1,000 per million population, respectively.

With regard to the most common blood purification method used in these regions, the ratio of $\mathrm{HD}$ to $\mathrm{PD}$ among prevalent dialysis patients in Japan was 96.9:3.1, indicating that PD use is extremely low; the ratio in the United States was 91.0:9.0. These proportions were more similar to those of prevalent patients than to those of incident patients (table $1 \mathrm{~b}$ ). In addition, over the previous 6 years, the ratio between HD and PD use among prevalent dialysis patients did not differ significantly, suggesting that each country has its own treatment of choice.

The mean age of prevalent dialysis patients has been increasing in both Japan and the United States since 1982, due to the increased number of patients aged $\geq 65$. How-

Dialysis Patients in Japan and Other Countries ever, the proportion of prevalent dialysis patients aged $\geq 65$ at the end of 2012 was $38.4 \%$ in the United States, $42.0 \%$ in Europe, and $59.8 \%$ in Japan, indicating that patients are aging rapidly in Japan (fig. 1).

With regard to kidney transplantation, the rate was 55.2 per million population in the United States and 3050 per million population in most European countries as of December 2012. Compared with these high rates, the rate of kidney transplantation in Japan was as low as 12.6 per million population and is characterized by a large proportion of living donors.

Another unique characteristic of Japanese dialysis patients is that large numbers undergo dialysis for an extended period of time, primarily because of the low rate of kidney transplantation. Figure 2 shows chronological changes over 5-year periods between 1992 and 2012 in the number of Japanese dialysis patients based on duration of dialysis and stratified by age. The proportion of patients with a duration of dialysis of $\geq 25$ years can be seen to have increased from $1.0 \%$ to $7 \%$ over a 10 -year period. Thus, not only the age of dialysis patients, but also the number of patients undergoing dialysis for lengthy periods has been increasing.

Table 2 shows patient characteristics based on the duration of dialysis. As the years of dialysis increased, body mass index decreased in a linear fashion, whereas single-pool Kt/V increased gradually. In addition, except for certain years, levels remained largely the same 
Fig. 2. Proportion of patients based on du-

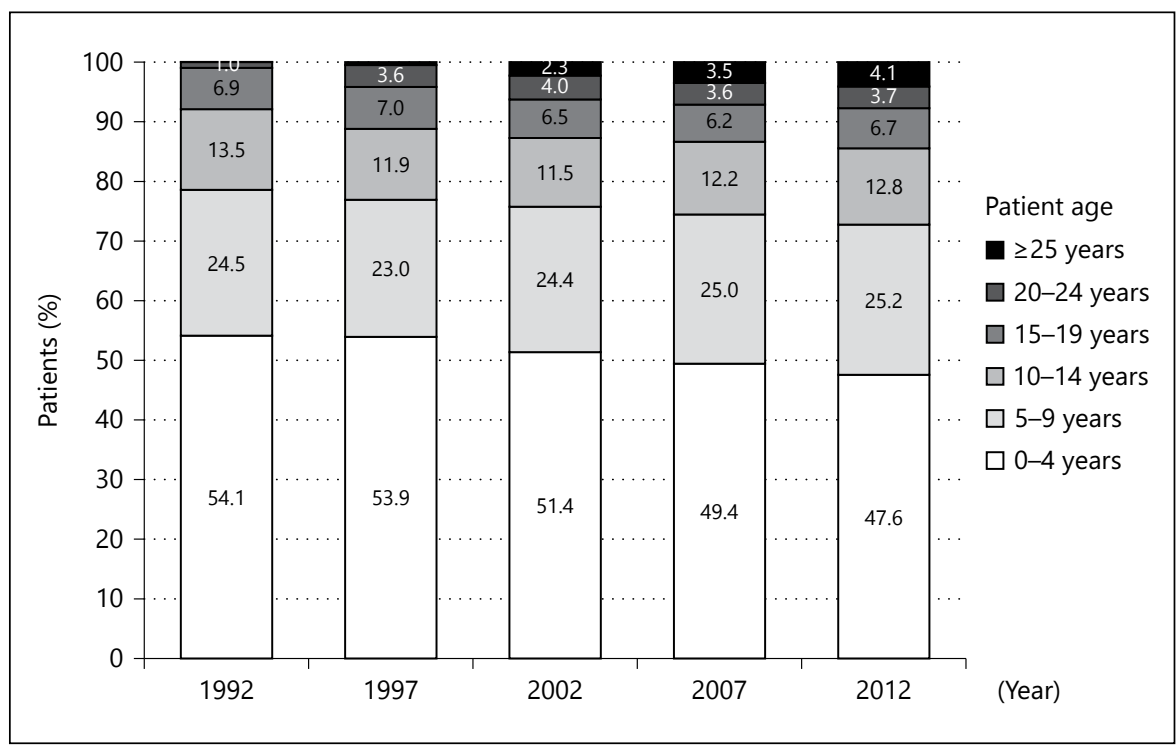
ration of dialysis (as of December 2012).

Table 2. Patient characteristics based on duration of dialysis in Japan

\begin{tabular}{llllllll}
\hline $\begin{array}{l}\text { Duration of } \\
\text { dialysis, years }\end{array}$ & BMI & spKt/V & nPCR, g/kg/day & pre-Hb, g/dl & pre-Alb,g/dl & pre-Ca, mg/dl pre-IP, mg/dl \\
\hline$<2$ & $21.9 \pm 3.9$ & NA & NA & $10.5 \pm 1.4$ & $3.6 \pm 0.5$ & $9.1 \pm 0.9$ & $5.1 \pm 1.4$ \\
$2-5$ & $22.0 \pm 4.0$ & $1.39 \pm 0.3$ & $0.85 \pm 0.17$ & $10.6 \pm 1.2$ & $3.7 \pm 0.4$ & $9.3 \pm 0.9$ & $5.2 \pm 1.5$ \\
$5-9$ & $21.6 \pm 3.8$ & $1.46 \pm 0.3$ & $0.87 \pm 0.18$ & $10.6 \pm 1.3$ & $3.6 \pm 0.4$ & $9.4 \pm 0.9$ & $5.3 \pm 1.5$ \\
$10-14$ & $21.0 \pm 3.5$ & $1.53 \pm 0.3$ & $0.89 \pm 0.18$ & $10.7 \pm 1.3$ & $3.7 \pm 0.4$ & $9.5 \pm 0.9$ & $5.3 \pm 1.4$ \\
$15-19$ & $20.5 \pm 3.2$ & $1.57 \pm 0.3$ & $0.91 \pm 0.18$ & $10.7 \pm 1.2$ & $3.7 \pm 0.4$ & $9.5 \pm 1.0$ & $5.3 \pm 1.4$ \\
$20-24$ & $20.1 \pm 3.0$ & $1.60 \pm 0.3$ & $0.92 \pm 0.17$ & $10.7 \pm 1.2$ & $3.7 \pm 0.4$ & $9.5 \pm 1.0$ & $5.2 \pm 1.3$ \\
$25-29$ & $20.0 \pm 3.0$ & $1.61 \pm 0.3$ & $0.92 \pm 0.17$ & $10.6 \pm 1.2$ & $3.6 \pm 0.4$ & $9.5 \pm 1.0$ & $5.2 \pm 1.3$ \\
$30-34$ & $19.8 \pm 2.8$ & $1.59 \pm 0.3$ & $0.91 \pm 0.18$ & $10.6 \pm 1.3$ & $3.6 \pm 0.4$ & $9.5 \pm 1.1$ & $5.1 \pm 1.3$ \\
$35-39$ & $19.5 \pm 2.7$ & $1.59 \pm 0.3$ & $0.90 \pm 0.19$ & $10.5 \pm 1.3$ & $3.5 \pm 0.4$ & $9.4 \pm 1.0$ & $5.1 \pm 1.3$ \\
$\geq 40$ & $19.3 \pm 2.6$ & $1.62 \pm 0.4$ & $0.88 \pm 0.18$ & $10.3 \pm 1.5$ & $3.4 \pm 0.5$ & $9.5 \pm 1.0$ & $4.9 \pm 1.3$ \\
Mean & $21.5 \pm 3.8$ & $1.48 \pm 0.3$ & $0.88 \pm 0.18$ & $10.6 \pm 1.3$ & $3.6 \pm 0.4$ & $9.3 \pm 0.9$ & $5.2 \pm 1.4$ \\
\hline
\end{tabular}

$\mathrm{BMI}=$ Body mass index; spKt/V = single-pool Kt/V; $\mathrm{nPCR}=$ normalized protein catabolic rate; $\mathrm{Hb}=$ hemoglobin; Alb = albumin; $\mathrm{Ca}=$ calcium; $\mathrm{IP}=$ phosphorus.

for normalized protein catabolic rate (g/kg/day), hemoglobin, serum albumin, corrected calcium, and phosphorus. However, albumin tended to decrease in patients who had been undergoing dialysis for more than 35 years.

In summary, DOPPS has revealed that certain aspects of dialysis treatment are unique to Japan, but the factors contributing to the low mortality rate among Japanese patients are currently unknown. In Japan, dialysis patients are aging rapidly, and the incidence of diabetes - an important prognostic factor in prevalent dialysis patients-has been increasing every year and is approaching the rates observed in the United States and Europe. Despite these observations, it is unclear why the crude death rate among Japanese dialysis patients has not declined significantly. Further study is needed to clarify whether technological developments in dialysis treatment have contributed to the low crude death rate in Japan.

\section{Conflicts of Interest}

The authors have no conflicts of interest to declare. 


\section{References}

1 Goodkin DA, Bragg-Gresham JL, Koenig KG, Wolfe RA, Akiba T, Andreucci VE, Saito A, Rayner HC, Kurokawa K, Port FK, Held PJ, Young EW: Association of comorbid conditions and mortality in hemodialysis patients in Europe, Japan, and the United States: the Dialysis Outcomes and Practice Patterns Study (DOPPS). J Am Soc Nephrol 2003;14: 3270-3277.
2 Saran R, Li Y, Robinson B, Ayanian J, Balkrishnan R, Bragg-Gresham J, Chen JT, Cope E, Gipson D, He K, Herman W, Heung M, Hirth RA, Jacobsen SS, Kalantar-Zadeh K, Kovesdy CP, Leichtman AB, Lu Y, Molnar MZ, Morgenstern H, Nallamothu B, O'Hare AM, Pisoni R, Plattner B, Port FK, Rao P, Rhee CM, Schaubel DE, Selewski DT, Shahinian V, Sim JJ, Song P, Streja E, Kurella Tamura M, Tentori F, Eggers PW, Agodoa LY, Abbott KC: US Renal Data System 2014 Annual Data Report: epidemiology of kidney disease in the United States. Am J Kidney Dis 2015; 65(suppl1):A7.
3 ERA-EDTA Registry: ERA-EDTA Registry Annual Report 2013, Academic Medical Center, Department of Medical Informatics, Amsterdam, The Netherlands, 2015. http:// www.era-edta-reg.org/files/annualreports/ pdf/AnnRep2013.pdf. 